\title{
The Situation, Harm, Causes and Countermeasures of Scenic Spots Non-standard Language
}

\section{-----Taking Tianjin as An Example}

\author{
Shaofang Zhang \\ School of Social Adminstration \\ Tianjin Vocational Institute \\ Tianjin,300410 China
}

\begin{abstract}
Promote public services language specification established as the key point of National medium and long-term language reform and development of career planning. Scenic spots are an important part of public service. The nonstandard language phenomenon is partly disrupting the order of words, it will influence Chinese cultural Inheritance, and damage to the tourism scenic spot image, the image of the city and National image, confuse youth on the correct cognition of characters. Therefore, after full investigation and study analysis, we recognize the Subjective and objective reasons of non-standard language phenomenon, it includes, language itself, standards and regulations documents, standard consciousness is weak, the application level is not high, Supervision mechanism is not sound. Therefore, we should take more measures, strengthen propaganda and education, enhance the procedural standards, and strengthen supervision. We will promote the language application ability of Employee, Raise awareness of the specification, Speed up the language specification file, and improve the mechanism of language standardization of the scenic spot management, to promote the improvement of language specification of the scenic spot.
\end{abstract}

Keywords- Scenic Spots; Language; Specification

\section{INTRODUCTION}

The key premise of language standardization is to accurately transfer and exchange information, the degree of application specification of language community is one important indicator to measure the level of national, and spiritual development of material civilization, which has an important position and role in the national cultural heritage and national cultural security [1]. The current development of China's tourist attractions is rapid; the existence of a variety of non-standard language phenomenon repeatedly appears in the public, scenic construction specification language should be strengthened. This article on the basis of full investigation of the phenomenon in the scenic pots, explored the reasons and analyzed problems, and put forward to enhance the language specification level scenic suggestions, designed to provide practical ideas and methods for the construction of scenic language specification, promoted scenic language specification healthy and sustainable development.

\section{A DESCRIPTION OF THE SURVEY AND RESULTS}

In order to accurately grasp the status quo scenic Tianjin Grade A specification language, to provide facts and figures for the area based on the construction of the language specification. The research group from January to April 2014 in Tianjin Culture Expo class, urban style classes, folk and other types of leisure scenic all together there are 30 (5A class are 2, 4A level scenic spots are 8, 3A level scenic spot are $15,2 \mathrm{~A}$ level scenic are 5) conducted a field survey. It focused on scenic tour map (guide map), garden notes, tips, fire signage, scenic interpretation system, scenic sold directly related souvenirs. Use the way of staff taking pictures and interviews with the investigation. Task 588 shooting-related photos, from sorting out valid photo 540, then according to the text written in the language of the text representation, language translation, etc., sorting out the non-canonical text 287. All kinds of tourist attractions have existence of various levels of abnormal phenomena. After finishing classified according to the non-canonical texts, the results show that the current language does not regulate the scenic focused typos, wrong sentences, non-standard characters used, digital writing is not standardized, punctuation errors, mistakes and other aspects of foreign language translation. It does not regulate the main terms of employees working in the area that reflected in the use of dialect in varying degrees (see Table 1). 
Table 1 Non-canonical texts

\begin{tabular}{|c|c|c|c|}
\hline \begin{tabular}{l}
\multicolumn{1}{c}{ Non- } \\
canonical \\
texts
\end{tabular} & Examples & $\begin{array}{l}\text { Qua } \\
\text { ntity }\end{array}$ & $\begin{array}{l}\text { Percen } \\
\text { tage }\end{array}$ \\
\hline Typos & $\begin{array}{l}\text { "Not greedy for } \\
\text { thing" is wrong } \\
\text { written as "not } \\
\text { greedy for finance" }\end{array}$ & 70 & $24 \%$ \\
\hline $\begin{array}{l}\text { Wrong } \\
\text { sentences }\end{array}$ & $\begin{array}{l}\text { Distribution of } \\
\text { promotional } \\
\text { materials, wedding } \\
\text { photo shoot shall } \\
\text { not be carried out } \\
\text { within the park } \\
\text { advisory. } \\
\text { ("Consultation" } \\
\text { missing object) }\end{array}$ & 71 & $25 \%$ \\
\hline $\begin{array}{l}\text { Irregular } \\
\text { ities with } \\
\text { the word }\end{array}$ & $\begin{array}{l}\text { "Bicycles" is } \\
\text { wrong written as } \\
\text { "Ding put the bike." }\end{array}$ & 31 & $11 \%$ \\
\hline \begin{tabular}{l}
\multicolumn{2}{c}{ Digital } \\
writing is \\
not \\
standardized
\end{tabular} & $\begin{array}{l}\text { Plaque date of } \\
\text { writing is not } \\
\text { standardized }\end{array}$ & 34 & $12 \%$ \\
\hline $\begin{array}{l}\text { Punctuat } \\
\text { ion errors }\end{array}$ & $\begin{array}{l}\text { Do not panic, } \\
\text { said clear } \\
\text { where. "Idress } \\
\text { wrong. "" }\end{array}$ & 32 & $11 \%$ \\
\hline $\begin{array}{l}\quad \text { Foreign } \\
\text { language } \\
\text { translation } \\
\text { error }\end{array}$ & $\begin{array}{l}\quad \text { Water } \\
\text { guide } \\
\text { translated map } \\
\text { Tourist Map for } \\
\text { Tianjin Shuishang, } \\
\text { where the lack of } \\
\text { "Park" }\end{array}$ & 49 & $17 \%$ \\
\hline
\end{tabular}

Thus, non-standard situations scenic language is written mainly for typos, wrong sentences, followed by foreign language translation error, digital writing is not standardized, punctuation errors, irregularities with the word also accounted for a certain proportion of cases.

\section{SCENIC LANGUAGE PHENOMENON SERIOUSLY ENDANGER IRREGULARITIES}

Currently, the scenic language unstandardized signs are everywhere, which affects the accurate transmission of information and the normal exchange, damage regulate the normal order of words, the impact of Chinese cultural heritage, tourist attractions affect the image of the city's image and the country's image, confuse teenager correct understanding of the text. Only a profound understanding of the scenic irregularities with the word of serious harm, can scenic language abide by norms and regulations document, enhance the scenic language specification level.

Language is a particularly important part of all kinds of landscape and cultural manifestations Expo class landscape composition, application and standardize the level of their language represents the scenic spots of quality and image.
Scenic spots typos, not standardized with the word, wrong sentences, digital writing is not standardized, non-standard punctuation errors and other phenomena, often presents that the impression of scenic and cultural taste is not high, the resort without standardized impression affect tourists travel experience, there have loss of scenic image. Tourism is a city window of service industry, tourist attractions are the business card of the city, and scenic language does not regulate the phenomenon, which directly affects the image of the city.

\section{THE MAIN REASON FOR THE EXISTENCE OF THE PHENOMENON OF NON-STANDARD SCENIC LANGUAGES}

After analysis, the research group concludes that there are many reasons resulting in the scenic language phenomenon, mainly the following:

Tourism management department regulations are incomplete specification of language, the language specification is not in place. For example, in 2000, for the city Language Evaluation work, only Zhejiang and Jiangsu and few provinces carried out the urban language assessment into the tourist attractions, and worked out the development of tourism-related languages and regulations, such as Lishui Language Work Committee. Lishui City Tourism Bureau introduced "Lishui tourism industry system specification language work long-term planning," Gaoyang new Comfort travel Company issued the "language of words standardized management system." However, there are many areas of the country for lack of relevant language specification paid insufficient attention to. The language specification work became engaged in "wind", language specification work is not related to the tourism industry, scenic language than the extent of regulation in these areas and other areas of Jiangsu and Zhejiang there is a gap, the language needs to accelerate the pace of construction norms.

Blank or inconsistent regulatory documents led to the phenomenon of non-standardized digital writing. Year date written specification based primarily on two documents, one in 1995 the State Bureau of Technical Supervision issued "on the use of digital publication rule", which explicitly states that date represents the time required digits, and the year is generally not abbreviated. Second, in 2000 the State Council issued the "state administrative organs document processing approach", its Article 25: The digital documents, in addition to the written date, part number and order in the hierarchy of words, phrases, idioms, abbreviations, with rhetorical statement must be used as a morpheme digital characters, but you should use Arabic numerals. Both documents are not made on the "plaque banner" year of the date of the inscription states that "the plaque banner" neither the document nor the publication, in which the figures in the end you should use Arabic numerals or characters. It is caused by plaque Year date wording varied underlying causes. But to say the least writing plaque Year date should be at least a unified or consistent use of Arabic numerals, or uniform use of Chinese characters. However, the wording of the tourist attractions of many "plaque" year date is too casual, as presented to the high school in Tianjin revival Deng Zhou Memorial "Youth Education Base" Year plaque wording is 
"2001", Chinese and Arabic numerals mixed, such a problem should not happen again.

Employees have lower level of Linguistics. Survey data show that 33 percent of employees are college-educated and below, lower educational level is making its design interpretation system in the area, especially the variety of non-standard implementation of specific phenomena appear. For example, in a 4A scenic lawn, it erected "Do not pull and pick grass" sign, which is really confusing. Management office staff of the scenic area explained that the green signage is bought from a professional sign making company. Although people of the signs of the production, sale cannot shirk responsibility, but as long as the staff who purchase it have a certain level of language, it can better off, and it would not have such a thing laughable.

Competent authorities lack the language regulatory. Language department in charge of supervision and inspection of social language has a wide range, the general provisions of tourist attractions and other public service sectors Language Specification Language Committee is responsible for the task of building the industry, the lack of tourist attractions language does not regulate the phenomenon of regulatory responsibilities. Tianjin is the case; the regulatory tasks are directly under the jurisdiction of Tourism Language Committee. At the same time, the language of non-law enforcement department in charge of irregularities only plays the role of criticism and education, inadequate supervision, which is one of the important reasons of public services; including that tourism industry does not regulate the language emerging phenomenon.

Departments of tourism quality supervision have regulatory gaps with low public participation. Supervision Departments of tourism quality focus on regulatory quality of tourism services complaints and tourism market order, the scenic language specification of supervision is blank. Scenic language specifications supervisory become tasks of public and the media, and the participation of the public and the media to its current oversight is not high, enthusiasm is not enough.

\section{Key STRATEgIES TO SOlVE NON-STANDARD PHENOMENON OF SCENIC LANGUAGE PROBLEM}

To solve the problem of non-standard language should remedy based on reason, be targeted. So you can take the following key countermeasures.

We should have Multi-level language proficiency training. In scenic pots annually, the practitioners should get Mandarin standardization knowledge and training. According to the guide, missionary personnel and fire cleaning class logistics personnel, they were trained in different positions; training should be combined with scenic irregularities targeted for instance, to take individual training and brainstorm combining theory and practice ways to effectively improve the language proficiency of employees.

A platform is to carry out activities related to collectively improve everyone language specification level. In the Scenic pots, we should regularly or irregularly conduct various activities on-site tour guide, have tour guide talent show, have scenic "Woodpecker" action, etc. Through the practice of improving our language specification level, employees make a deep sense of homeland language charm; deepen the understanding of motherland language and the meaning of text, more consciously specification language words.

Continue to promote and improve the language proficiency of assessment system. Continue to promote Putonghua Proficiency Test, test and application level kanji Chinese Proficiency Test, policies and regulations to carry out the language proficiency test and verification activities, standardized Chinese writing contests and combine it with training activities, so that mutual promotion enhance the effect. In addition, we should attempt to establish practitioner's language proficiency professional standards in tourist attractions, in accordance with professional standards and requirements of the introduction of recruitment, training existing employees.

Strengthen the language standard procedures and seriousness. Language specification standards should adhere to the scientific program [7], namely, in-depth investigation and research - and solicit public views - published standard file - a timely review. Because the phenomenon of language itself and the complexity of public language, the language of the standard applications develop on the basis of full investigation and a lot of first-hand information on the full study language of justifications, system, not just do it in a way of so-called close doors. Language standards in various fields, different members of the community have their own standards for language understanding and requirements, and they have their own language usage. Therefore, the development of the language standard should listen to the relevant authorities, organizations, experts and the public fully demonstrate different views of the content. It should not mean " it is decided by us" Wide-ranging language standard is relatively stable and easy to change the language standard after releasing, which should be reviewed as soon as possible to identify problems in a timely manner to amend or repeal, otherwise, once a long time or it has been widespread used, it is difficult to amend. Developing language standards is to strictly abide by the program, valuing all aspects of the work, in order to ensure the language standard of seriousness, so that it can be recognized and consciously abided by the public, to avoid similar simplified scheme brought language confusion.

Accelerate the introduction of national and local tourist attractions management at all levels of the language specification files. Development and introduction of the language specification documents in tourism industry will lead to the successful development and rapid development of tourist attractions language standard construction work. For example, the development of national and local specification language in tourism industry system should work long-term planning, measures and steps to determine the goal of building the scenic language specification work. Development of the tourism industry with the word standardized terminology management system is to determine the tourist attractions, travel agencies, tourist and other scenic spots participation in the body language of words multiple specification documents. At the same time, the language norms are an important part of the scenic 
construction specifications to include A-level scenic spot assessment rules; we should try to develop the tourism industry language standard documents.

We should develop a sound system of the language specification. In order to make the scenic language has rules to follow. According to the National Tourism Administration Language Committee, Language Committee, Language employees to use Mandarin, Chinese character writing specifications, the provisions of scenic tour map, traffic maps, guidebooks, scenic travel guides, books, catalogs, advertising materials, all kinds of signs in compliance with all specifications and other languages on a regular basis on the scenic language and writing. We should check all the sites, and regulate the situation and urge the rectification, purification scenic language environment.

\section{CONCLUSIONS}

Improve the regulatory mechanism and the language incentive mechanisms. Appropriate law enforcement duties should be given to the top-level design language from the competent authorities. Increase the social norms of language use of word supervision; achieve the tourist attractions and other key areas of real-time monitoring the situation of the language specification. The language specification should be into line with language text competent authorities by the end of the scope of examination, we should timely reward and punish. In addition, language standardization work is a career of the mass, in addition to the scenic internal staff to carry out widespread self-examination and rectification activities. We need to guide the public to actively participate in the supervision of prizes to report, to carry out "Woodpecker action". Find and rectify scenic language abnormal phenomena.
Committee at all levels should carry out language work ideas and spirit. And it should combine with the specific circumstances of the scenic language specification to develop a sound system, the scenic language scenic standard construction specifications is as the important content of the declaration as a higher-level scenic important basis for alevel scenic spots that included assessment rules. Require

Acknowledgements:

Fund Project: Tianjin Philosophy and Social Science Planning 2013 annual research project (TJZWWT13-09), Tianjin Professional College 2013 Foundation of China (20132112)

\section{References}

[1] Huang Dekuan. The National Security Strategy of the language work [N]. China Education Daily, 2014-3-8 (8).

[2] I see the language specification [N]. Anhui Daily, 2003-9-18 (4)

[3] Zhong Longbiao, Liu Li. China's national image under the international tourism development context propagation $[\mathrm{J}]$ external communication, 2013 (07): 41-43.

[4] Chinese language network language standard library [EB / OL] .http: // www.

[5] china-language.gov.cn/wenziguifan/index.html, 2007-07-26.

[6] Liu Guangting, Cheng Lili. Strengthen the construction of Beijing language university, leading the National Capital Cultura Development - Situation Beijing university language specification analysis [J] Applied Linguistics, 2013 (3): 17-23

[7] She Shuchu. Yiwu tourist attractions language specification investigation [J] Lanzhou Institute of Education, 2013 (1): 29-31.

[8] Wang Cuiye. Review and Reflection Chinese Language Standardization[J] Applied Linguistics, 2005 (1): 44-50. 